\title{
KAP STUDY
}

\section{Assessment of Knowledge, Attitudes and Practices towards Nutrition amongst Adolescents in Karachi}

\author{
Kashaf Aqeel Zaidi', Wajeeha Mahmood', Farah Ahmad ${ }^{2}$ \\ 'Student, Ziauddin Medical College, Ziauddin University, ${ }^{2}$ Department of Community Health Sciences, \\ Ziauddin Medical College, Ziauddin University, Karachi, Pakistan.
}

\begin{abstract}
Background: The association between health and nutrition are eminent. Quality nutrition is acknowledged as one of the most important determinants of optimal development, good health, and wellbeing. Therefore, the study aimed to determine the knowledge, attitudes, and practices amongst adolescents regarding nutrition.

Methods: It was a cross-sectional study conducted between 2016 to 2017 in Karachi. The sample size was 384; the purposive sampling technique was applied with a target population of adolescents between 14 and 19 years of age. Informed consent was taken before the questionnaire submission. Data were collected via self-administered questionnaires from students of various schools in Karachi. The Chi square test was applied for associations and a $p$-value of $<0.05$ was considered statistically significant.
\end{abstract}

Results: The mean age of 394 adolescents was (mean \pm SD) $17.08 \pm 1.63$ years and found female predominance $282(71.6 \%)$. The average weight of the participants was $58.60 \pm 18.58$. Protein $305(77.4 \%)$ was the most widely consumed food. Breakfast was seen as the most important meal of the day among $213(54.1 \%)$ all participants. There was a significant association between healthy dietary habits and the frequency of exercise per week ( $p$-value $=0.001$ ). Only $57(14.5 \%$ ) followed a specific meal plan and the mostly 151 (38.3\%) not following a meal plan was due to lack of time.

Conclusion: Most of the adolescents $87(22.2 \%)$ understand the importance of various food nutrients. However, appropriate nutritional practices were not found in the majority of the adolescents, possibly due to the lack of time and sedentary lifestyle.

Keywords: Nutritional Quality; Adolescent Medicine; Non-Communicable Diseases.

\section{Corresponding Author: \\ Kashaf Aqeel Zaidi}

Ziauddin Medical College,

Ziauddin University, Karachi, Pakistan.

Email: kashafazaidi@gmail.com

https://doi.org/10.36283/PJMD10-1/016

\section{INTRODUCTION}

Nutrition is the intake of food, according to the body's dietary needs. Good nutrition comprises of an adequate, well balanced diet combined with regular physical activity; these are keystones of good health'. Body mass index (BMI) is an important indicator of health and nutrition in individuals and half of the Pakistani population has a BMl within the normal range, which is between $18.5-24.9 \mathrm{~kg} / \mathrm{m}^{2}$ compared to
South Asian adolescents 2 . Since $22.3 \%$ of the Pakistani population comprises adolescents, this makes nutritional awareness amongst adolescents critical to ensure that the young adults of the future have a healthy base ${ }^{3}$. Adolescence is characterized by increased energy and nutrient requirements along with changes in dietary habits, which introduces nutritional problems ${ }^{4}$. The number of overweight/obese adolescents has tripled in the last 30 years, particularly in females ${ }^{5,6}$. This has contributed 
to an increase in the prevalence of various conditions including Type II diabetes mellitus, hypertension, and arteriosclerosis ${ }^{7}$. Moreover, micronutrient deficiencies including Vitamin A, Vitamin D, folate, iron and iodine are a major health concern in developing countries 8 .

A comparative study has shown a remarkable increase in deranged BMl and associated problems owing to unhealthy eating habits and sedentary lifestyles ${ }^{6}$. According to a study conducted in Pakistan, $17 \%$ of the students were underweight, $65 \%$ were normal weight and $18 \%$ were

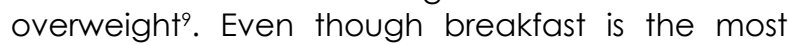
nutritious meal of the day, two studies conducted in Europe and Ireland showed half the study group did not consume breakfast'. A study conducted in Karachi identified that $85 \%$ of the students were leading a sedentary lifestyle but when they were asked about ways to lose weight, $96 \%$ listed exercise among their answers ${ }^{10,11}$.

Many studies have been conducted to determine the prevalence and causes of nutritional deficiencies in Pakistan. However, very little research has been conducted to determine the source and accuracy of the nutritional information being delivered to adolescents, which will be an important aspect of this study. Since health education interventions in schools have been successful in reducing levels of obesity amongst adolescents and future risk of non-communicable diseases ${ }^{12}$, therefore suitable measures can be taken to improve subsequent influence on health. The study aimed to determine the knowledge, attitudes, and practices amongst adolescents regarding nutrition.

\section{METHODS}

This was a cross-sectional study conducted from November 2016-October 2017. The sample size was $n=384$ based on a prevalence of $50 \%$ knowledge regarding nutrition with a bound of error of $1 \%$ and a confidence level of 95. The sample was selected using a purposive sampling technique. Institutional ethical approval was taken from Ziauddin University. The inclusion criteria were based on adolescents aged between 14-19 years, currently enrolled in a private school at similar levels of education. Exclusion criteria included those who were suffering from a medical condition that affected their dietary habits or spoke a language other than English.

A self-designed questionnaire was used to collect data. Students from various schools in Karachi were approached for data collection after obtaining consent from the schools. Moreover, consent was obtained from the participants before filling out the questionnaire. Data was entered and analyzed using SPSS version 20. Frequencies and percentages were calculated for categorical variables, mean and standard deviation (SD) was calculated for numerical data. Pearson Chi Square test was used to find associations between various qualitative variables of interest. For all purposes, a p-value of $<0.05$ was considered statistically significant.

\section{RESULTS}

The sample population consisted of $n=394$ adolescents between 14-19 years of age. Mean age of adolescents investigated was $17.08 \pm 1.63$ years. The sample was predominantly female $\mathrm{n}=282(71.6 \%)$ and the average weight recorded was $58.60 \pm 18.58$. The average height was 5 feet 6 inches \pm 3 inches.

Table 1: Nutritional practices among adolescents

\begin{tabular}{|c|c|c|c|c|}
\hline \multicolumn{5}{|c|}{ Dietary habits and practices of adolescents } \\
\hline \multirow{2}{*}{$\begin{array}{l}\text { Most widely consumed } \\
\text { food }\end{array}$} & $\begin{array}{c}\text { Proteins } \\
\text { n (\%) }\end{array}$ & $\begin{array}{l}\text { Grains } \\
\text { n (\%) }\end{array}$ & $\begin{array}{c}\text { Dairy } \\
\text { products } \\
\text { n (\%) } \\
\end{array}$ & $\begin{array}{c}\text { Fruits and } \\
\text { vegetables } \\
\text { n (\%) }\end{array}$ \\
\hline & $\begin{array}{l}305 \\
77.4 \\
\end{array}$ & $\begin{array}{c}n=205 \\
52.0\end{array}$ & $\begin{array}{c}n=245 \\
62.2\end{array}$ & $\begin{array}{c}n=215 \\
54.6\end{array}$ \\
\hline \multirow[b]{2}{*}{$\begin{array}{l}\text { Most important meal of } \\
\text { the day }\end{array}$} & Breakfast & Lunch & \multicolumn{2}{|c|}{ Dinner } \\
\hline & $\begin{array}{c}n=213 \\
54.1\end{array}$ & $\begin{array}{l}n=89 \\
22.6\end{array}$ & \multicolumn{2}{|c|}{$\begin{array}{l}n=89 \\
22.6\end{array}$} \\
\hline \multirow{2}{*}{$\begin{array}{l}\text { How often do you skip } \\
\text { breakfast? }\end{array}$} & Always & Sometimes & \multicolumn{2}{|c|}{ Never } \\
\hline & $\begin{array}{c}n=40 \\
10.2\end{array}$ & $\begin{array}{c}n=137 \\
34.8\end{array}$ & \multicolumn{2}{|c|}{$n=127$} \\
\hline
\end{tabular}




\begin{tabular}{|c|c|c|c|c|}
\hline \multirow{2}{*}{$\begin{array}{l}\text { Reason for skipping } \\
\text { breakfast }\end{array}$} & $\begin{array}{c}\text { Running late } \\
\text { for school }\end{array}$ & Not hungry & \multicolumn{2}{|c|}{ No help in preparing it } \\
\hline & $\begin{array}{c}n=141 \\
35.8\end{array}$ & $\begin{array}{c}n=112 \\
28.4\end{array}$ & \multicolumn{2}{|c|}{$\begin{array}{c}n=14 \\
3.6\end{array}$} \\
\hline \multirow{2}{*}{$\begin{array}{l}\text { Daily water consumption } \\
\text { (number of glasses) }\end{array}$} & Less than 5 & \multicolumn{3}{|c|}{ At least 5 or more } \\
\hline & $\begin{array}{c}n=137 \\
34.8\end{array}$ & \multicolumn{3}{|c|}{$\begin{array}{c}n=257 \\
65.2\end{array}$} \\
\hline \multirow{2}{*}{$\begin{array}{l}\text { Factors considered when } \\
\text { choosing a meal }\end{array}$} & Taste & Convenience & Price & Healthy food \\
\hline & $\begin{array}{c}n=259 \\
65.7\end{array}$ & $\begin{array}{c}n=35 \\
8.9\end{array}$ & $\begin{array}{c}n=34 \\
8.6\end{array}$ & $\begin{array}{c}n=66 \\
16.8\end{array}$ \\
\hline \multirow{2}{*}{$\begin{array}{l}\text { What kind of lifestyle do } \\
\text { you have? }\end{array}$} & Traditional & Sedentary & \multicolumn{2}{|c|}{ Active } \\
\hline & $\begin{array}{c}n=152 \\
38.6\end{array}$ & $\begin{array}{l}n=92 \\
23.4\end{array}$ & \multicolumn{2}{|c|}{$\begin{array}{c}n=150 \\
38.1\end{array}$} \\
\hline \multirow{2}{*}{$\begin{array}{l}\text { How often do you } \\
\text { exercise per week? }\end{array}$} & Everyday & $\begin{array}{l}\text { Once a } \\
\text { week }\end{array}$ & $\begin{array}{c}\text { Twice a } \\
\text { week }\end{array}$ & $\begin{array}{c}\text { Thrice a week } \\
\text { or more } \\
\end{array}$ \\
\hline & $\begin{array}{c}n=42 \\
10.7\end{array}$ & $\begin{array}{l}n=87 \\
22.1\end{array}$ & $\begin{array}{l}n=67 \\
17.0\end{array}$ & $\begin{array}{l}\mathrm{n}=84 \\
21.3\end{array}$ \\
\hline
\end{tabular}

Proteins were the most widely consumed nutrient in $305(77.4 \%)$ participants (Table 1). Only 205(52\%) of the adolescents had grains daily. Dairy products were consumed by $245(62.2 \%)$ every day. Fruits and vegetables were consumed daily by $215(54.6 \%)$ and $191(48.5 \%)$ of the population, respectively. Water was one of the most neglected portions of the daily intake in $137(34.8 \%)$ of the participants with consumption of fewer than 5 glasses of water every day whereas, $257(65.2 \%)$ of the adolescents were drinking at least 5 glasses of water each day.

The majority $222(56.3 \%)$ of the participants ate out once a week and most of the people denied eating out very frequently. Some important factors that people consider while choosing a meal were identified. Only 66(16.8\%) opted for a health-based meal and $259(65.7 \%)$ chose taste as their priority. A small percentage $35(8.9 \%)$ and $34(8.6 \%)$ of the adolescents listed convenience and price as their utmost priority, respectively.

More than half the sample, 213(54.1\%) identified breakfast as the most important. However, $89(22.6 \%)$ and $75(19 \%)$ considered lunch and dinner as their priority, respectively. Despite understanding the importance of breakfast, only $127(32.2 \%)$ were having it every day. On the other hand, 40(10.2\%) always skipped breakfast and the majority $137(34.8 \%)$ mentioned skipping breakfast sometimes. $141(35.8 \%)$ mentioned skipping it because they are running late for school, whereas, $112(28.4 \%)$ claimed that they do not feel hungry in the morning.

A decent understanding was found in the adolescent age group regarding physical exercise as $280(71.1 \%)$ was exercising. Out of $280(71.1 \%)$, the highest percentage of $87(22.1 \%)$ was of who preferred exercising once a week. The majority of adolescents $129(32.7 \%)$ exercise for about half an hour to 1 hour and restricted themselves to less than half an hour and the rest worked out for more than an hour each time. However, when asked about lifestyles, the majority $152(38.6 \%)$ claimed to have a traditional lifestyle and $92(23.4 \%)$ sedentary. 


\section{Eating habits and gastrointestinal problems}

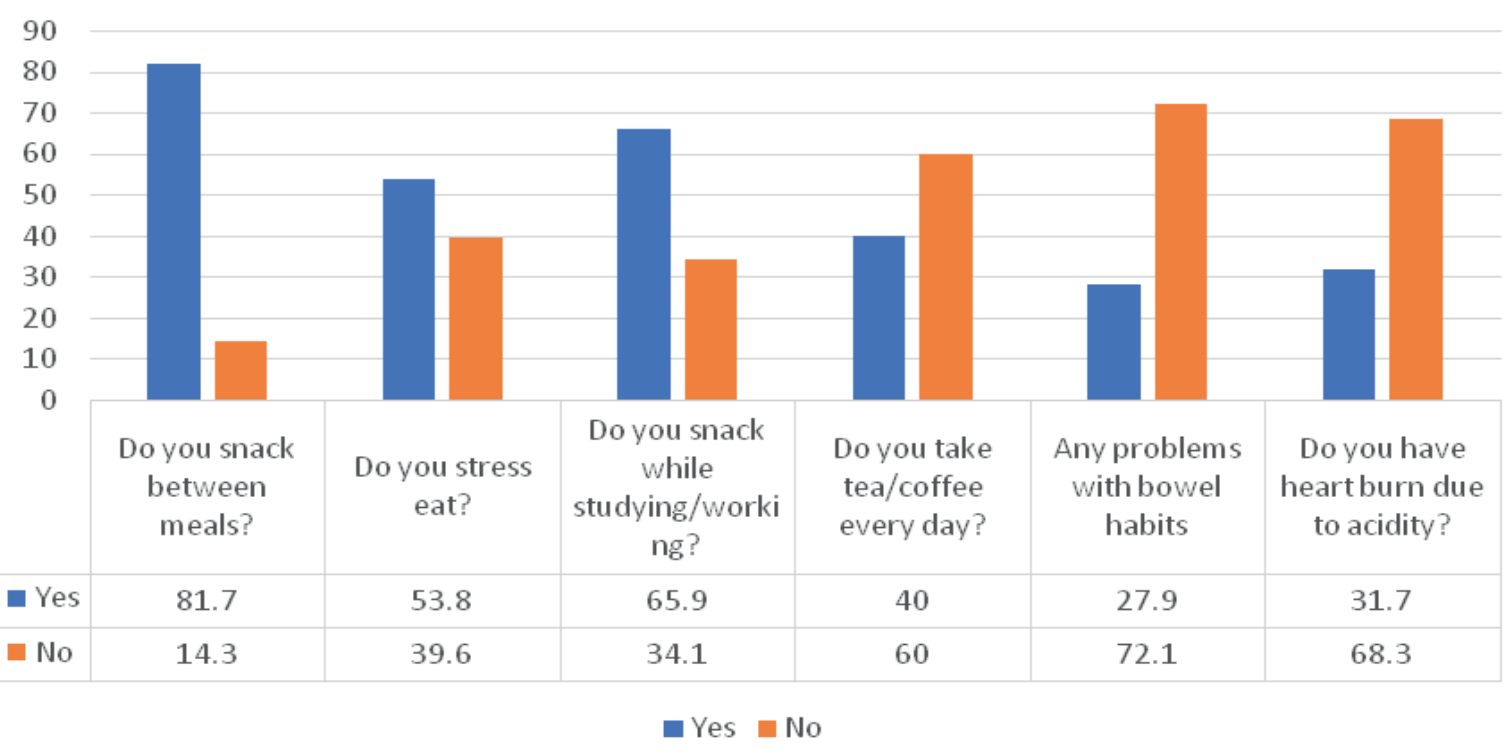

Figure 1: Eating habits and associated gastrointestinal problems.

Among eating habits and health related concerns, snacks, chips, cookies, and fried items were consumed by $117(29.7 \%), 64(16.2 \%)$ and $36(9.1 \%)$, respectively (Figure 1). On the other hand, fruits were consumed by $109(27.7 \%)$. The majority of the adolescents 125(31.8\%) preferred working/studying in the evening which might explain the consumption of snacks. Whereas, 116(29.4\%) preferred mornings followed by 93(23.5\%) who preferred late night studying. The majority of the adolescents $208(52.9 \%)$ were sleeping for 7-8 hours every day. However, $130(32.9 \%)$ were getting only 5-6 hours of sleep or less. There was no significant association found between the hours of sleep they get and the level of physical activity.

Table 2: Association of diet, exercise, and medical problems.

\begin{tabular}{|l|c|c|}
\hline \multirow{2}{*}{ How often do you exercise per week? } & \multicolumn{2}{|c|}{$\begin{array}{c}\text { Do you think your habits are healthy? } \\
\text { Value }\end{array}$} \\
\cline { 2 - 3 } & Healthy & 17 \\
\hline Everyday & 25 & 53 \\
\hline Once a week & 34 & 41 \\
\hline Twice a week & 26 & 42 \\
\hline Thrice a week or more & 42 & 84 \\
\hline Never & \multicolumn{2}{|c|}{3001} \\
\hline \multirow{2}{*}{ How often do you skip breakf ast? } & \multicolumn{2}{|c|}{ Do you consume snacks? } \\
\hline Never & Consumed & Unconsumed \\
\hline Sometimes & 104 & 27 \\
\hline Very often & 115 & 22 \\
\hline Always & 73 & 13 \\
\hline \multirow{2}{*}{ How often do you exercise per week? } & 30 & 10 \\
\hline Everyday & Do you have any medical problems? \\
\hline Once a week & Medical History & Healthy \\
\hline Twice a week & 9 & 33 \\
\hline Thrice a week or more & 19 & 68 \\
\hline Never & 11 & 54 \\
\hline
\end{tabular}


A significant association (Table 2) was found between the frequency of physical exercise and the participant perception of whether their dietary habits are healthy or not ( $p$-value $=0.001)$. The majority of the people who exercised daily believed they had healthy eating habits. Moreover, there was a rising trend in the perception of healthy habits with the number of days an individual exercised. Moreover, contrary to normal perception, a significant association was not found between snack consumption and the habit of skipping breakfast in adolescents ( $p$-value $=0.438$ ). The association between exercise and experiencing medical problems was insignificant ( $p$-value $=0.484)$.
Following specific meal plans was not a common practice with only $57(14.5 \%)$. Amongst those following a plan, 37(9.4\%) had made it for themselves, 21 (5.3\%) was following the one given by their parents and only $5(1.3 \%)$ were relying on one provided by a professional dietician. Out of $337(85.5 \%)$ of the population that was not following a specific plan, majority $151(38.3 \%)$ stated it was due to the lack of time. Moreover, $87(22.2 \%)$ stated that they felt healthy with their current style of eating and $99(25.1 \%)$ claimed that they have a balanced diet and do not feel the need for a specific diet plan. Most of the participants (Figure 2) correctly identified the functions of Vitamin A, D, C, zinc, sodium, and iron. However, the majority were unable to identify the functions of Vitamin B and $\mathrm{K}$.

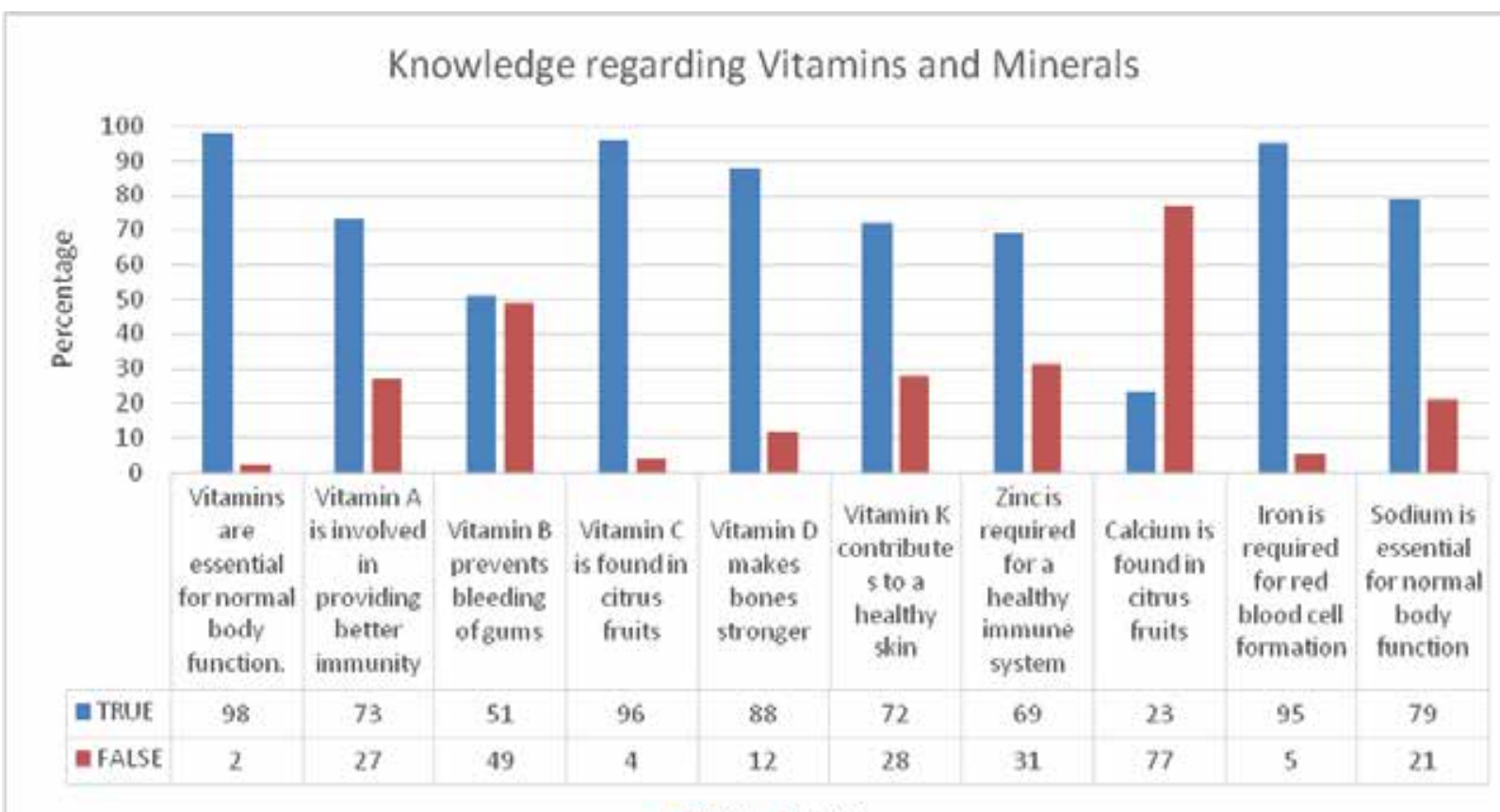

- TRUE a FALSE

Figure 2: Knowledge of adolescents regarding the functions of vitamins and minerals.

\section{DISCUSSION}

Adolescence is a group that requires good nutritional practices as it is the final period of growth and development and it has been identified as a high-risk age group for the development of obesity ${ }^{13}$. Moreover, the eating habits developed at this age are more likely to persist throughout adulthood therefore; interventions in this age group prove to be more effective ${ }^{14}$. Thus, more attention needs to be paid to the adolescent age group to decrease the incidence of non-communicable, chronic diseases in the older population ${ }^{15}$. A study conducted in 2003 in Pakistan amongst the adolescent age group showed $17 \%$ people were underweight, $65 \%$ were in the normal range, $18 \%$ were overweight, and since then extremes of weight have been on a rise ${ }^{10}$.
Various factors contribute to the development of eating habits, including family environment, cultural makeup and socioeconomic status of the adolescents ${ }^{16}$. These factors determine the rejection and acceptance of various foods and may even encourage unhealthy eating. Studies have confirmed that intake of fast food is associated with parents who directly attempt to control the dietary habits ${ }^{17}$.

Furthermore, eating out was also recognized as a significant health hazard and hence majority (56.3\%) ate only once a week and only $6.1 \%$ claimed to eat out every day. A study has reported that adolescents consume half the recommended number of fruits and vegetables, less than two-thirds of the recommended amount of milk products and consume more fats and sweets ${ }^{18}$. Our study also revealed similar results and showed dairy products consumption by a majority (62.2\%) everyday. 
The most consumed food nutrient was proteins as they were regarded as one of the richest sources of energy. Grains, despite being a part of the staple diet in Pakistan, were only consumed by $52 \%$ of adolescents. Therefore, emphasis needs to be laid on the consumption of fruits and vegetables. Similarly, a study has shown that there is more reliance on fruit juices and other sweetened beverages and the water was still consumed by the largest percentage of adolescents ${ }^{19}$. Our study is consistent with these findings, $65.2 \%$ of the study group was having at least 5 glasses of water a day.

Studies conducted in the West have shown that food choices were primarily based on convenience and hence the widespread availability of rich caloric foods with low nutritional value has led to their increased consumption ${ }^{20}$. Other major barriers identified to healthy eating comprised of cravings for unhealthy, rich food that predominantly contains fats ${ }^{21}$. However, in our study results, $65.7 \%$ of participants made food choices based on taste and only $16.8 \%$ opting for healthy food.

Studies have shown that adolescents who consume breakfast regularly have lower body fat content and healthy cardiovascular profile ${ }^{22}$. Thus, an attempt was made to understand the youth's opinion on the most important meal of the day, which was correctly identified as breakfast (54.1\%). Previous studies have also shown similar results with half the population not consuming breakfast ${ }^{23}$. The most common reason listed for missing breakfast was being late for school or college as opposed to previous literature in which the main reason was not feeling hungry ${ }^{16}$.

A significant proportion of the study group was found to be suffering from medical problems related to the alimentary tract, which included irregular bowel movements (27.9\%), and chest burn due to acidity (31.7\%). These problems occurring at such a young age and are directly associated with unhealthy, eating habits. Hence, there is a need to improve eating habits by providing appropriate knowledge and introducing effective interventions.

In accordance with previous studies, a reasonable understanding was seen amongst adolescents regarding exercise. The majority $(71.1 \%)$ of the population claimed they were doing physical exercise on a regular basis 9 . However, only $10.9 \%$ were exercising every day, this is mainly due to an increased workload from schools and colleges at this age, which leaves lesser time for formal exercise.

Furthermore, sleep is known to have a major impact on the lifestyle of an individual. Studies have revealed that individuals who sleep at least 7 hours are more likely to be active in the hours that they are awake ${ }^{24}$. Our study showed similar results as amongst those who slept 5-6 hours, only 9.2\% exercised daily. There was no significant association between the number of sleep- ing hours and engagement in physical activity. Therefore, interventions are required to inculcate healthy eating habits, encourage physical exercise regularly and improving sleeping habits ${ }^{25}$.

According to the results, adolescents exhibited a variable understanding of important vitamins for instance role of Vitamin $B$ and $K$ in bleeding gums and healthy skin, respectively. However, they seemed to have more sound knowledge about various minerals as they correctly identified the roles of zinc, iron, and sodium. Majority of the study group did seem to have above average knowledge but further enhancement of it could improve their dietary practices. Previous studies have shown that the main source of information for adolescents were friends $(71 \%)$ and television $(52 \%)^{14}$. Various studies have established that an unhealthy lifestyle has multiple contributory factors to it. This includes the family setup, order of the child amongst siblings, socioeconomic status, frequency of various food groups' consumption and spending time on television and computers, which inevitably reduces time spent on outdoor activities ${ }^{17}$.

\section{CONCLUSION}

Mostly adolescents understand the importance of food nutrients especially vitamins and minerals. However, appropriate nutritional practices were not found in the majority of the adolescents. This highlights the importance of health education and timely intervention in this age group with particular importance for stress reducing practices.

\section{ACKNOWLEDGEMENTS}

We would like to acknowledge Ziauddin University for allowing us to conduct this study.

\section{CONFLICT OF INTEREST}

There is no conflict of interest among the authors in this study.

\section{ETHICS APPROVAL}

The Ziauddin University granted an institutional approval for the study.

\section{PATIENT CONSENT}

There were no patients involved in the study. The study was conducted on healthy adolescents and consent was taken prior to filling of the forms.

\section{AUTHORS' CONTRIBUTION}

KAZ designed the questionnaire, collected data, analyzed data, and wrote the manuscript. WM suggested the topic, did literature review and partial analysis. FA supervised the research and helped with sampling and reviewing the manuscript. 


\section{REFERENCES}

1. Nutrition [Internet]. Who.int. 2020 [cited 18 Sep 2020]. Available from: http://www.who.int/topics/nutrition/en/

2. Khan K, Jameel N, Khalil R, Gul S. Exploring nutritional status, physical activity and body mass index of Pakistani teens. Int Journal Res Med Sci. 2016:4:3563-3569

3. UNICEF Pakistan [Internet]. Unicef.org. 2020 [cited 18 Sep 2020]. Available from: http://www.unicef. org/infobycountry/pakistan_pakistan_statistics.html 4. Das J, Salam R, Thornburg K, Prentice A, Campisi $S$, Lassi $Z$, et al. Nutrition in adolescents: physiology, metabolism, and nutritional needs. Ann N York Acad Sci. 2017;1393(1):21-33

5. Obesity and overweight [Internet]. Who.int. 2020 [cited 18 Sep 2020]. Available from: https://www.who.int/news-room/fact-sheets/detail/obesity-and-overweight

6. Cureau F, Sparrenberger K, Bloch K, Ekelund U, Schaan B. Associations of multiple unhealthy lifestyle behaviors with overweight/obesity and abdominal obesity among Brazilian adolescents: A country-wide survey. Nutr Metab Cardiovasc Dis. 2018;28(7):765-774

7. Bay J, Morton S, Vickers M. Realizing the potential of adolescence to prevent transgenerational conditioning of noncommunicable disease risk: multi-sectoral design frameworks. Healthc. 2016:4(3):39.

8. Mohd FMN, Devi NR, Suraiami M. Vitamin A in health and disease. Vitamin A [Internet]. 2019 [cited 18 Sep 2020]; Available from: https://www.researchgate.net/publication/332551578_Vitamin_A_ in_Health_and_Disease

9. Hallström L, Vereecken CA, Labayen I, Ruiz JR, Le Donne C, Garcia MC, et al. Breakfast habits among European adolescents and their association with sociodemographic factors: the HELENA (Healthy Lifestyle in Europe by Nutrition in Adolescence) study. Public Health Nutr. 2012.15:1879-1889.

10. Rehman T, Rizvi Z, Siddiqui U, Ahmad S, Sophie A, Siddiqui $M$, et al. Obesity in adolescents of Pakistan. J Pak Med Assoc. 2003;53:315-319.

11. Wignall J. Supporting \& promoting adolescent nutritional health equity. Adolesc Nutr. 2020. Springer, Cham. pp. 239-268.

12. Aziz S, Noorulain W, Zaidi UR, Hossain K, Siddiqui IA. Prevalence of overweight and obesity among children and adolescents of affluent schools in Karachi. J Pak Med Assoc. 2009;59(1):35-38.

13. Carrasco J, Gombert M, Carrasco-García Á, Codoñer-Franch P. Adolescent feeding: Nutritional risk factors. J Child Sci. 2018;08(01):e99-e105.

14. Dietz WH. Critical periods in childhood for the development of obesity. Am J Clin Nutr. 1994 59(5):955-959.
15. Haynos A, Wall $M$, Chen C, Wang S, Loth K, Neumark-Sztainer D. Patterns of weight control behavior persisting beyond young adulthood: Results from a 15-year longitudinal study. Int J Eat Disord. 2018;51(9):1090-1097.

16. Nirmala A, Kanniammal C, Venkataraman $P$, Judie A. Predisposing factors associated with obesity among adolescents-A case control study. Biomed Res. 2018;29(18).

17. Kolodinsky J, Battista G, Roche E, Lee B, Johnson R. Estimating the effect of mobility and food choice on obesity in a rural, northern environment. J Transp Geogr. 2017;61:30-39.

18. Lipowska $M$, Lipowski $M$, Jurek $P$, Jankowska $A$, Pawlicka P. Gender and body-fat status as predictors of parental feeding styles and children's nutritional knowledge, eating habits and behaviours. Int $\mathrm{J}$ Environ Res Public Health. 2018;15(5):852-867.

19. Diethelm K, Jankovic N, Moreno LA, Huybrechts I, De Henauw S, De Vriendt $T$, et al. Food intake of European adolescents in the light of different foodbased dietary guidelines: results of the HELENA (Healthy Lifestyle in Europe by Nutrition in Adolescence) Study. Public Health Nutr. 2012; 15:386-398. 20. Sui $Z$, Zheng $M$, Zhang $M$, Rangan $A$. Water and beverage consumption: Analysis of the Australian 2011-2012 national nutrition and physical activity survey. Nutrients. 2016;8(11):678-692.

21. Peltner J, Thiele S. Convenience-based food purchase patterns: identification and associations with dietary quality, sociodemographic factors and attitudes. Public Health Nutr. 2017;21 (03):558-570.

22. Tiedje K, Wieland ML, Meiers SJ, Mohamed AA, Formea CM, Ridgeway JL, et al. A focus group study of healthy eating knowledge, practices, and barriers among adult and adolescent immigrants and refugees in the United States. Int J Behav Nutr Phys Act. 2014;11(1):63-76.

23. Hallström L, Labayen I, Ruiz JR, Patterson E, Vereecken CA, Breidenassel C, et al. Breakfast consumption and CVD risk factors in European adolescents: the HELENA (Healthy Lifestyle in Europe by Nutrition in Adolescence) Study. Public Health Nutr. 2013.16:1296-1305

24. Ardeshirlarijani $E$, Namazi $N$, Jabbari $M$, Zeinali $M$, Gerami H, Jalili RB, et al. The link between breakfast skipping and overweigh/obesity in children and adolescents: A meta-analysis of observational studies. J Diabetes Metab Disord. 2019:1-8.

25. Gariépy G, Doré I, Whitehead R, Elgar F. More than just sleeping in: a late timing of sleep is associated with health problems and unhealthy behaviours in adolescents. Sleep Med. 2019; 56:66-72.

26. Pereira SM, Power C. Early adulthood determinants of mid-life leisure-time physical inactivity stability and change: Findings from a prospective birth cohort. J Sci Med Sport. 2018;21 (7):720-726. 